\title{
Spatial and temporal patterns of the inter-annual oscillations of glacier mass over Central Asia inferred from Gravity Recovery and Climate Experiment (GRACE) data
}

\author{
ZHU Chuandong ${ }^{1,2^{*}}$, LU Yang ${ }^{1,2}$, SHI Hongling ${ }^{1,2}$, ZHANG Zizhan ${ }^{1,2,3}$ \\ ${ }^{1}$ State Key Laboratory of Geodesy and Earth's Dynamics, Chinese Academy of Sciences, Wuhan 430077, China; \\ ${ }^{2}$ University of Chinese Academy of Sciences, Beijing 100049, China; \\ ${ }^{3}$ Center for Space Research, University of Texas at Austin, Austin 78759, USA
}

\begin{abstract}
Monitoring glacier mass balance is crucial to managing water resources and also to understanding climate change for the arid and semi-arid regions of Central Asia. This study extracted the inter-annual oscillations of glacier mass over Central Asia from the first ten principal components (S-PCs) of filtered variability via multichannel singular spectral analysis (MSSA), based on gridded data of glacier mass inferred from Gravity Recovery and Climate Experiment (GRACE) data obtained from July 2002 to March 2015. Two significant cycles of glacier mass balance oscillations were identified. The first cycle with a period of 6.1 -year accounted for $54.5 \%$ of the total variance and the second with a period of 2.3 -year accounted for $4.3 \%$. The 6.1-year oscillation exhibited a stronger variability compared with the 2.3-year oscillation. For the 6.1-year oscillation, the results from lagged cross-correlation function suggested that there were significant correlations between glacier mass balances and precipitation variations with the precipitation variations leading the response of glacier mass balances by $9-16$ months.
\end{abstract}

Keywords: Gravity Recovery and Climate Experiment; glacier mass balance; multichannel singular spectral analysis; Central Asia

Citation: ZHU Chuandong, LU Yang, SHI Hongling, ZHANG Zizhan. 2017. Spatial and temporal patterns of the inter-annual oscillations of glacier mass over Central Asia inferred from Gravity Recovery and Climate Experiment (GRACE) data. Journal of Arid Land, 9(1): 87-97. doi: 10.1007/s40333-016-0021-z

\section{Introduction}

Mountain glaciers are important components of the hydrologic cycles and the climate systems (Immerzeel et al., 2010; Gardner et al., 2013). In general, glaciers provide valuable water resources for natural ecosystems and also for human activities in mountain regions and the adjacent lowlands. In particular, water resources originating from mountain glaciers contribute reliable water supplies to the fragile ecosystems and also to human activities in the arid and semi-arid regions of Central Asia (Yao et al., 2004; Unger-Shayesteh et al., 2013). Equally important is the fact that the mountain glaciers are extremely sensitive to climate change (Stocker et al., 2013). And, the sensitivity was well documented over Central Asia (Lioubimtseva and Henebry, 2009; Sorg et al., 2012; Farinotti et al., 2015; Kononova et al., 2015; Xu et al., 2015).

Local geodetic and glaciological measurements were commonly used to estimate glacier mass

*Corresponding author: ZHU Chuandong (E-mail: zhuchuandong@asch.whigg.ac.cn)

Received 2015-11-04; revised 2016-03-03; accepted 2016-03-15

(C) Xinjiang Institute of Ecology and Geography, Chinese Academy of Sciences, Science Press and Springer-Verlag Berlin Heidelberg 2017 
balance (Yao et al., 2012). However, these measurements are only applicable to local scales. Monitoring large-scale glacier mass balance has recently become possible with the launch of the Gravity Recovery and Climate Experiment (GRACE) mission. The GRACE mission, consisting of twin coplanar low-altitude satellites, is the first satellite dedicated to gravity mission. Jointly sponsored by NASA and the German Aerospace Center (DLR) and launched in March 2002, GRACE has been providing measurements of the Earth's gravity field with spatial resolution of several hundred kilometers and temporal resolution of about one month (Tapley et al., 2004a). The GRACE data sets can provide direct and quantitative estimates of glacier mass through the inversion of time variable gravity change, especially for the regions where in situ measurements are difficult or impossible (Tapley et al., 2004b; Luthcke et al., 2008; Jacob et al., 2012; Schrama et al., 2014). The spatial patterns of glacier mass have been previously delineated from GRACE data for Central Asia (Matsuo and Heki, 2010). However, the temporal patterns remain to be depicted.

With improved GRACE accuracies and newly-developed data processing techniques, the longer-term and continuous observations allow us investigate the temporal patterns (Sasgen et al., 2010; Chen et al., 2011; de Linage et al., 2013). This study takes advantage of the newly-developed techniques and longer-term observations to extract the inter-annual oscillations of glacier mass over Central Asia from the first ten principal components (S-PCs) of filtered variability by performing multichannel singular spectral analysis (MSSA).

\section{Data processing and methods}

\subsection{Study area}

In this study, Central Asia refers to the region comprising the Turkmenistan, Uzbekistan, Tajikistan, Kyrgyzstan and Kazakhstan, as well as northwestern China (Cowan, 2007). Some ice-existing regions in Afghanistan and Pakistan are also included for comparison purpose (Jacob et al., 2012; Yi and Sun, 2014). The ice-covered regions in Central Asia (including those in Afghanistan and Pakistan) are mostly concentrated on the Tianshan Mountains and the Pamir Plateau (Fig. 1). The Tianshan Mountains extend from eastern Uzbekistan to eastern Xinjiang of China with a total length of $2500 \mathrm{~km}$. The total area reaches $390 \times 10^{3} \mathrm{~km}^{2}$ with $14 \times 10^{3} \mathrm{~km}^{2}$ covered with ice (glaciers). The Pamir Plateau is actually a mountain knot of three ranges (i.e., Himalaya, Karakoram, and Hindukush). The total area reaches $60 \times 10^{3} \mathrm{~km}^{2}$ with $30 \times 10^{3} \mathrm{~km}^{2}$ covered with ice (glaciers). These glaciers feed major rivers over Central Asia (e.g., Tarim, Amu

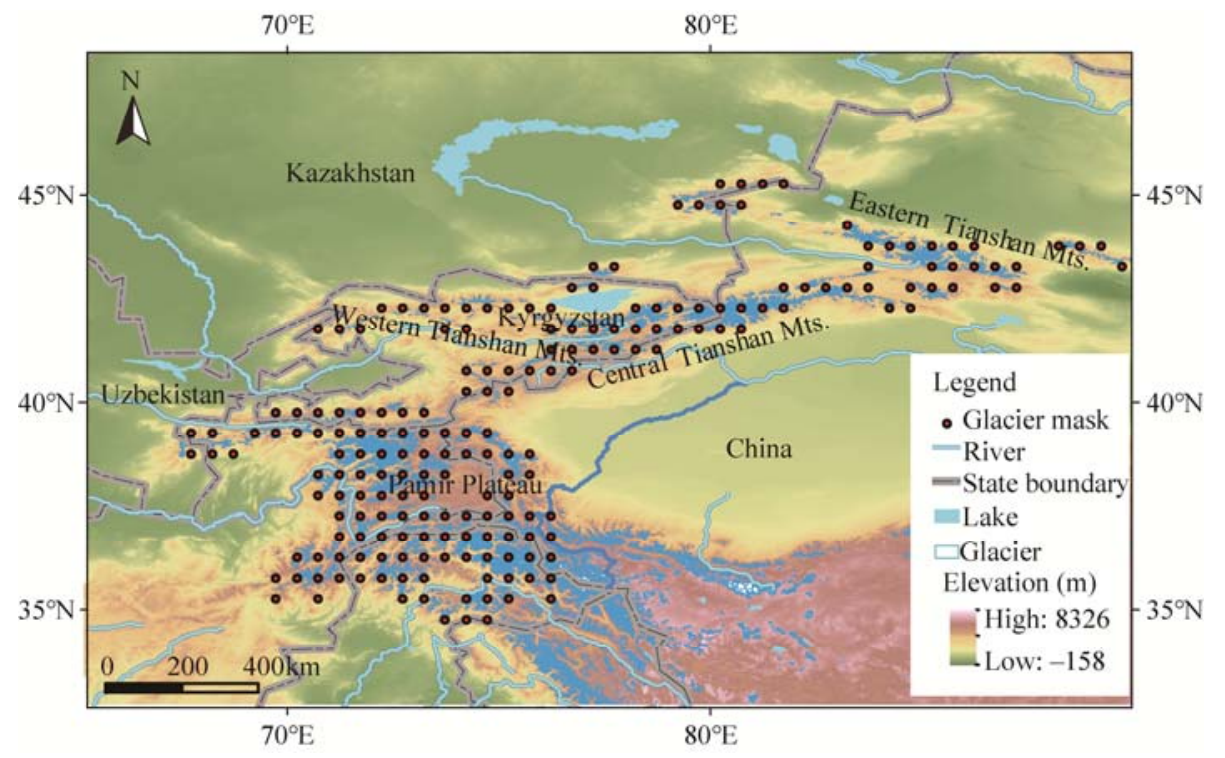

Fig. 1 Locations of glaciers over Central Asia 
Darya, and Syr Darya), and the variations in glacier mass will thus directly impact the downstream runoff.

\subsection{Data processing}

As shown in Figure 1, the Randolph Glacier Inventory was used to construct the glacier mask $\left(0.5^{\circ} \times 0.5^{\circ}\right.$ grid) over Central Asia (Arendt et al., 2012). The GRACE gravity field spherical harmonic coefficients (SHC's, Level 2 (L2) Data Products; Bettadpur, 2003) were used to compute the glacier mass. Monthly GRACE data sets were obtained from the University of Texas's Center for Space Research (CSR). Because the atmospheric and oceanic mass changes and tidal effects were presumably removed from GRACE L2 RL05 data, the GRACE gravity field variations primarily reflect the combined effects of ice, snow, waters stored on the surface and in the ground. The variations also contain signal of solid earth effects associated with the ongoing viscoelastic response of the Earth crust and mantle to ice load variability (Chen et al., 2006; Velicogna and Wahr, 2006). We used the GRACE L2 RL05 data covering the period from July 2002 to March 2015 to estimate the glacier mass. It should be particularly pointed out that the GRACE L2 RL05 data were significantly improved over RL04 data in terms of accuracy and also over Level-1B data in terms of data processing techniques (Chambers and Bonin, 2012).

Due to the orbit geometry and the short separation between two satellites $(220 \mathrm{~km})$, the time-dependent variable, gravity field coefficients (i.e., $C_{20}$ value), cannot be reliably determined from the GRACE observations. Thus, we replaced the GRACE-based $C_{20}$ estimate with more reliable value derived from satellite laser range (Cheng and Tapley, 2004). In addition, the SHC's (i.e., $C_{10}, C_{20}$ and $S_{11}$ ) in degree-1 were cited from the estimates of Swenson et al. (2008) for no provision in GRACE solutions. Also, a decorrelation filter P11M5 (Swenson and Wahr, 2006) was applied to reduce the influence of longitudinal strips, and a 300-km Gaussian filter (Wahr et al., 1998) was further applied to damp the GRACE errors for removing the contamination of SHC's in high degrees and orders. The means of all 141 monthly solutions were then removed to obtain time series of gravity field variations $\left(\delta C_{l m}(t), \delta S_{l m}(t)\right)$.

To single out of the signal of glacier mass, we used monthly-scale soil moisture estimates at $0.25^{\circ} \times 0.25^{\circ}$ resolution from the Global Land Data Assimilation System (GLDAS/Noah) to remove soil moisture-related hydrological effects (Rodell et al., 2004). Besides, a model of glacial isostatic adjustment (GIA) was adopted to remove solid Earth effects (Geruo et al., 2013). The GLDAS and GIA gridded fields were then converted to SHC's and the SHC's were then truncated into the same degrees and orders with GRACE gravity field. After the Gaussian filter was applied, the SHC's of GLDAS and GIA were removed from time series of gravity field variations $\left(\delta C_{l m}(t)\right.$, $\left.\delta S_{l m}(t)\right)$.

The processed values of SHC's were then used to compute monthly glacier mass over the glacier mask following the method described by Wahr et al. (1998). The missing values of 11 months in the 141 monthly time series of glacier mass were interpolated by least-squares method. Figure 2 shows the patterns in equivalent water height over Central Asia after removing GIA and surface water variations. As shown in Figure 2, the spatial patterns of glacier mass in Central Asia were highly heterogeneous, and an obvious loss of glacier mass occurs in the eastern margin of the Tianshan Mountains.

\subsection{Methods}

As a non-parametric technique and the extension of singular spectral analysis (SSA), multi-channel singular spectral analysis (MSSA) can be used to extract the known and unknown oscillations from noisy spatio-temporal data (Vautard and Ghil, 1989). The extracted oscillations by MSSA can be modulated in amplitude and phase, being consistent with the intrinsically nonlinear dynamics of climate change (Plaut and Vautard, 1994). Given the strong seasonal variability in glacier mass, a 13-month running mean was applied to extract the inter-annual variability. Firstly, the principal component analysis (PCA) was performed on the normalized glacier data set. The first ten principal components (S-PCs) in the PCA analysis were then chosen 


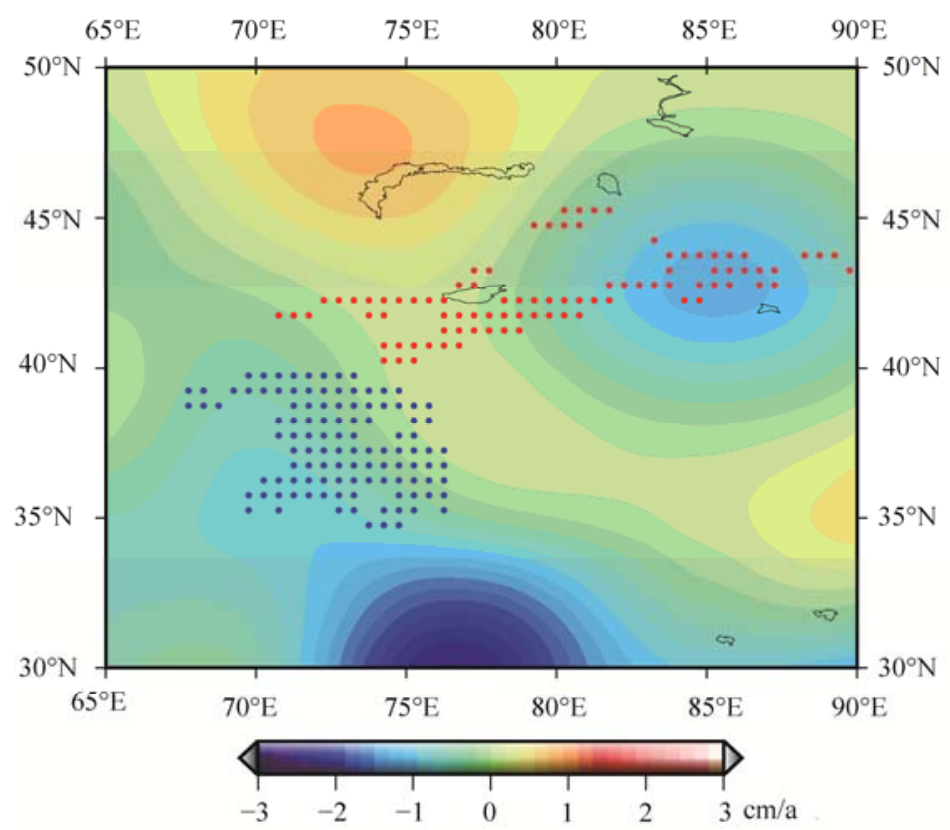

Fig. 2 Spatial patterns in equivalent water height over Central Asia after removing glacial isostatic adjustment (GIA) and surface water variabilities in the Tianshan Mountains (red) and the Pamir Plateau (blue)

for the subsequent MSSA study (Plaut and Vautard, 1994; Ghil et al., 2002). According to Vautard et al. (1992), a proper use of a window length $M$ in a time series analysis can successfully isolate the oscillations with certain periodicities and the window length is a critical user-prescribed parameter that defines the spectral resolution of the algorithm. Moreover, the choice of $M$ is a trade-off between quantity of information extracted (a large $M$ ) and the degree of statistical confidence in that information (as many repetitions as possible) (Ghil et al., 2002). For a dataset $\left\{X_{l}(t): l=1, \ldots, L ; t=1, \ldots, T\right\}$, which is a multivariate time series with $L$ variables (channels) and length $T$, the starting point of MSSA computational algorithm is to embed each channel into a phase space of dimension $M$ with a sliding window of length $M$ (i.e., $X_{l}(t)=\left(X_{l}\left((t), X_{l}\left((t+1), \ldots, X_{l}((t+M-1), t=1, \ldots, T-M+1)\right.\right.\right.$. Thus, the columns and length trajectory matrix can be obtained. The specific algorithm is as follows:

The block-Toeplitz matrix $\widetilde{T_{X}}$ then can be formed by

$$
\widetilde{T_{X}}=\left(\begin{array}{ccc}
T_{1,1} & \cdots & T_{1, L} \\
\vdots & \ddots & \\
T_{L, 1} & & T_{L, L}
\end{array}\right) .
$$

Each block $T_{l, l}$ is the $M \times M$ lag covariance matrix between channel $l$ and channel $l$ '. As discussed in Plaut and Vautard (1994), the estimate of the entries (l,l') in each block $T_{l, l^{\prime}}$ can be calculated as:

$$
\left(T_{l, l^{\prime}}\right)_{j, j^{\prime}}=\frac{1}{N-\left|j-j^{\prime}\right|} \sum_{i=1}^{N-\left|j-j^{\prime}\right|} X_{l i} X_{l^{\prime} i+j-j^{\prime}} .
$$

Next, diagonalizing the $L M \times L M$ matrix $\widetilde{T_{X}}$ gives the eigenvalues and associated eigenvectors (also called space-time empirical orthogonal functions, i.e., ST-EOFs $\left\{E_{l}^{k}: 1<k \leq L M\right\}$. The eigenvalues are then arranged in decreasing order and help to find the amount of covariance contributed by each mode. Projecting the original series $X$ onto the ST-EOFs yields space-time principal components, i.e., ST-PCs. 


$$
P C^{k}(n)=\sum_{j=1}^{M} \sum_{l=1}^{L} X_{l}(n+j-1) E_{l}^{k}(j),
$$

with $k=1, \ldots, L M$ and $n=1, \ldots, T-M+1$.

Finally, the original time series are decomposed into reconstructed component (RC) by convolving corresponding ST-EOF with ST-PC (Plaut and Vautard, 1994).

$$
R_{l}^{k}(t)=\left\{\begin{array}{cc}
\frac{1}{t} \sum_{j=1}^{t} P C_{t-j}^{k} E_{l}^{k}(j) & 1 \leq t \leq M-1 \\
\frac{1}{M} \sum_{j=1}^{M} P C_{t-j}^{k} E_{l}^{k}(j) & M \leq t \leq N-M+1 . \\
\frac{1}{N-t+1} \sum_{j=t-N+M}^{M} P C_{t-j}^{k} E_{l}^{k}(j) & N-M+2 \leq t \leq N
\end{array}\right.
$$

According to Plaut and Vautard (1994), oscillatory components are formed by pairs of ST-EOFs and their associated ST-PCs and can be determined through three fundamental properties of MSSA: (1) two consecutive eigenvalues are nearly equal; (2) two corresponding time sequences described by the ST-EOFs are nearly periodic in the same period and in quadrature; and (3) the associated ST-PCs are in quadrature.

\section{Results and discussion}

\subsection{Inter-annual oscillations in glacier mass}

\subsubsection{Inter-annual oscillatory pairs}

The largest possible window length of 76 was used to extract the inter-annual oscillations. Thus the $L M=10 \times 76=760$, and the size of the covariance matrix to be diagonalized is $760 \times 760$. Figure 3 shows the eigenvalue spectra of the first 50 ST-PCs of glacier mass from GRACE data. The error bars in Figure 3 are based on the ad hoc estimate of variance $\sigma_{k}$ of an eigenvalue $\lambda_{k}$ given by $\sigma_{k}=(2 / \hat{N}) \lambda_{k}$, where $\hat{N}$ is the maximum number of degrees of freedom in the time series (Unal and Ghil, 1995). And the confidence level of $95 \%$ in Figure 3 is obtained from eigenvalues produced by running MSSA on 100 random monthly data sets (Ghil et al., 2002). As shown in Figure 3, the first eight eigenvalues that pass the test at the $95 \%$ confidence level account for $95.6 \%$ of the total variance.

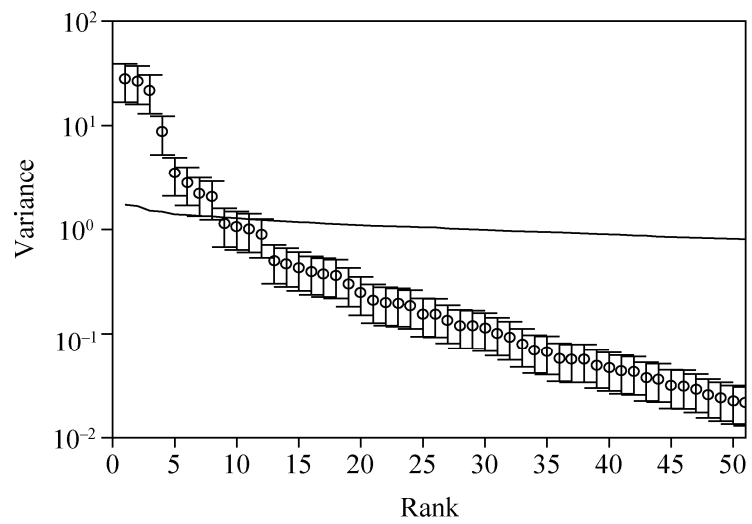

Fig. 3 The eigenvalue spectra of the first 50 space-time principal components (ST-PCs) of glacier mass from Gravity Recovery and Climate Experiment (GRACE) data

Figure 4 shows the eight corresponding ST-EOFs and ST-PCs, individually or in pairs. The third and fourth ST-EOFs and ST-PCs that represent long-term variations account for $21.8 \%$ and $8.8 \%$ of the total variance, respectively. Since the ST-EOFs and their associated ST-PCs are well 

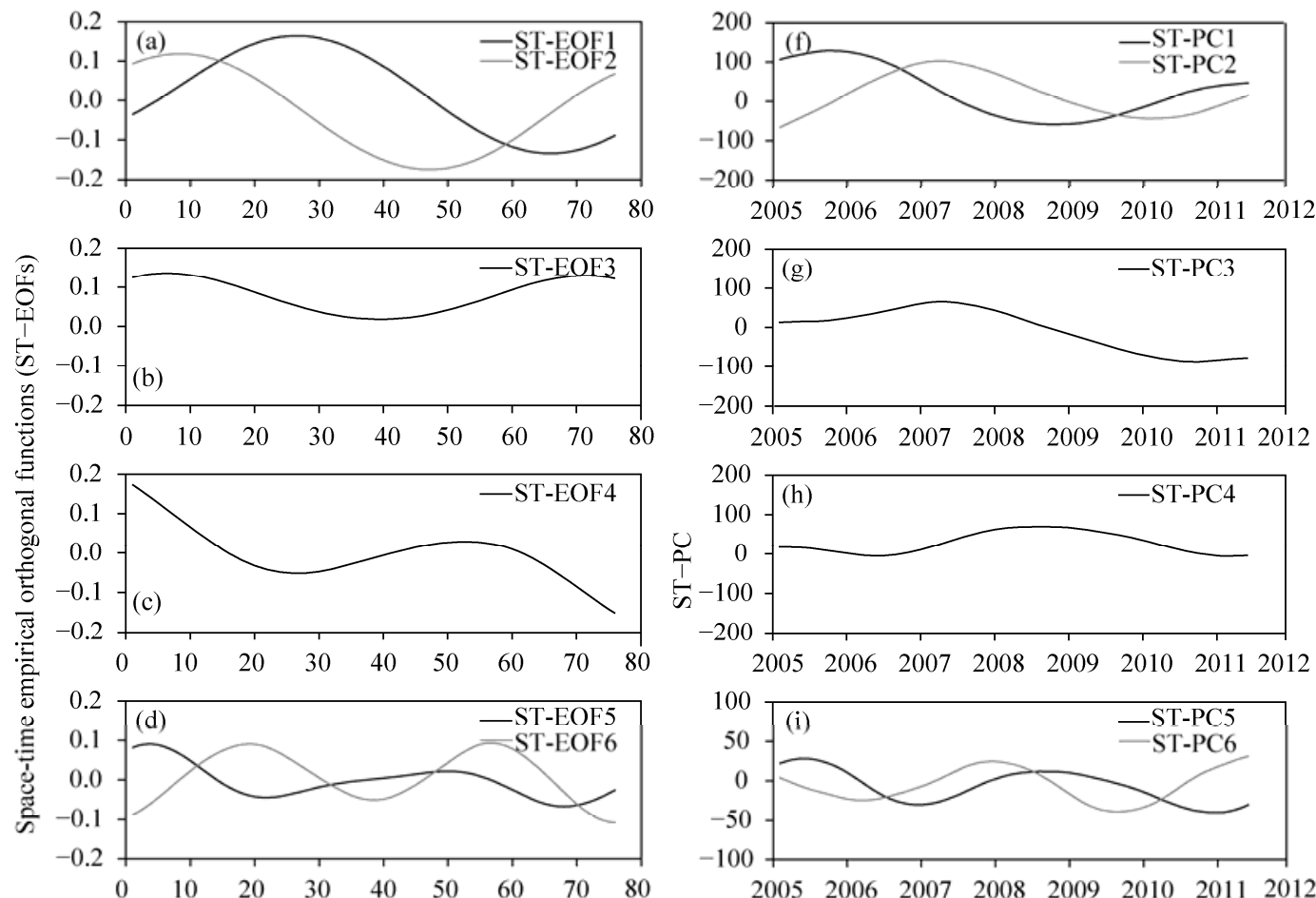

20052006200720082009201020112012
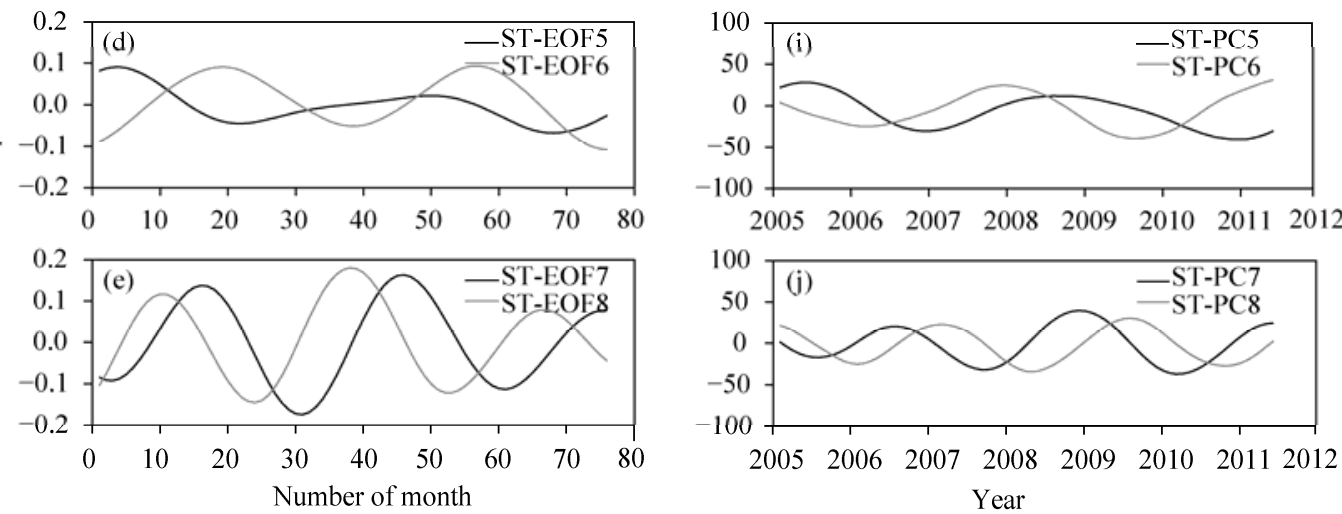

Fig. 4 The first eight space-time empirical orthogonal functions (ST-EOFs) and space-time principal components (ST-PCs) of glacier mass

in quadrature, the nearly identical eigenvalues of 1 and 2, 7 and 8 from three potential oscillatory pairs account for $54.5 \%$ and $4.3 \%$ of the total variance, respectively.

In previous studies, two spurious jumps were found in the atmosphere and ocean de-aliasing level-1b (AOD1B) data, which may cause uncertainties in the estimates of regional glacier mass (Duan et al., 2012). Hence, the L2 GAC data computed from 6-hourly AOD1B data sets were restored to GRACE data to correct the atmospheric effects. Table 1 shows the variabilities of the GRACE glacier mass and the corrected atmospheric effects of the six eigenmodes. The fact that the variance differences between the GRACE glacier mass and the corrected atmospheric effects are within $0.2 \%$ seems to suggest that the results of oscillatory pairs was barely affected by the atmospheric effects.

Table 1 The variabilities of Gravity Recovery and Climate Experiment (GRACE) glacier mass and corrected atmospheric effects of six eigenmodes

\begin{tabular}{ccc}
\hline Eigenmodes & $\begin{array}{c}\text { Case 1: variance in GRACE glacier } \\
\text { mass } \\
(\%)\end{array}$ & $\begin{array}{c}\text { Case 2: variance in the corrected } \\
\text { atmospheric effects } \\
(\%)\end{array}$ \\
\hline $1 \& 2$ & 54.5 & 54.3 \\
3 & 21.8 & 21.8 \\
4 & 8.8 & 8.8 \\
78 & 4.3 & 4.4 \\
\hline
\end{tabular}




\subsubsection{Patterns of the inter-annual oscillations}

For each channel $l$, the oscillatory components $\operatorname{RC} 12$ and $\operatorname{RC} 78$ for the eigenmodes $(1,2)$ and $(7$, 8) were obtained by adding the two RCs of each oscillatory pair. Using the maximum entropy method (Burg, 1967), two oscillatory components with periodicities of 6.1-year and 2.3-year were identified from the channel $l$ that has a maximum variance (Fig. 5).

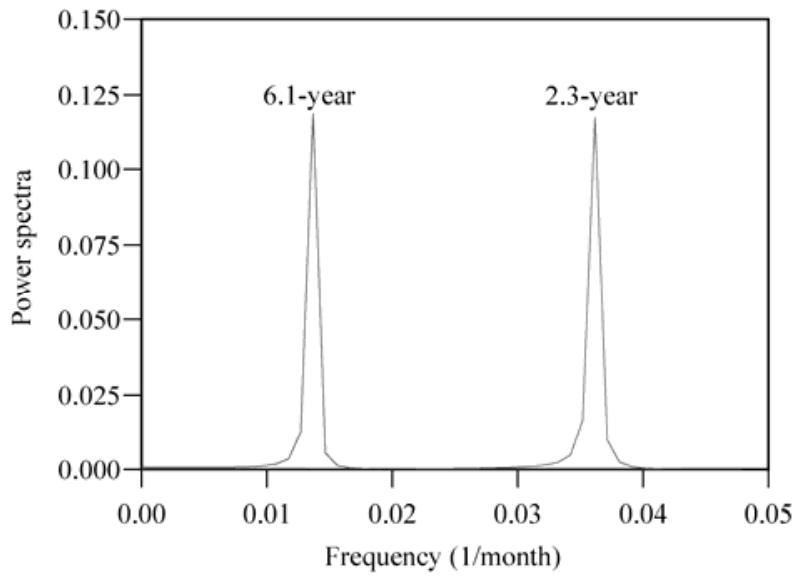

Fig. 5 Power spectra from channel $l$ that has a maximum variance in RC12 (6.1-year) and RC78 (2.3-year)

As described in Section 1.3, space-time series of these two oscillatory components (STRCs) can be estimated as:

$$
\operatorname{STRCs}(x, t)=\sum_{l=1}^{10} S-\operatorname{EOF}(l)(x) \times R C s_{t}^{l} .
$$

Where $x$ is the position of grid point over ice-covered regions and $t$ represents time. Figure 6 shows the differences in spatial patterns of the 6.1-year and 2.3-year oscillations between extreme high and extreme low phases, The extreme high and extreme low phases are defined as the maximum and minimum peaks of the STRC at each grid point. The difference in the 6.1-year oscillation is high in the Pamir Plateau and also in the eastern Tianshan Mountains (Fig. 6a), and, the maximum value (up to $9.6 \mathrm{~cm}$ ) occurs on the edge of the western Hindukush. However, the difference in the 2.3-year oscillation (Fig. 6b) is much lower in comparison with that in the 6.1 -year oscillation and the maximum value (only $2.6 \mathrm{~cm}$ ) occurs on the eastern Pamir Plateau.
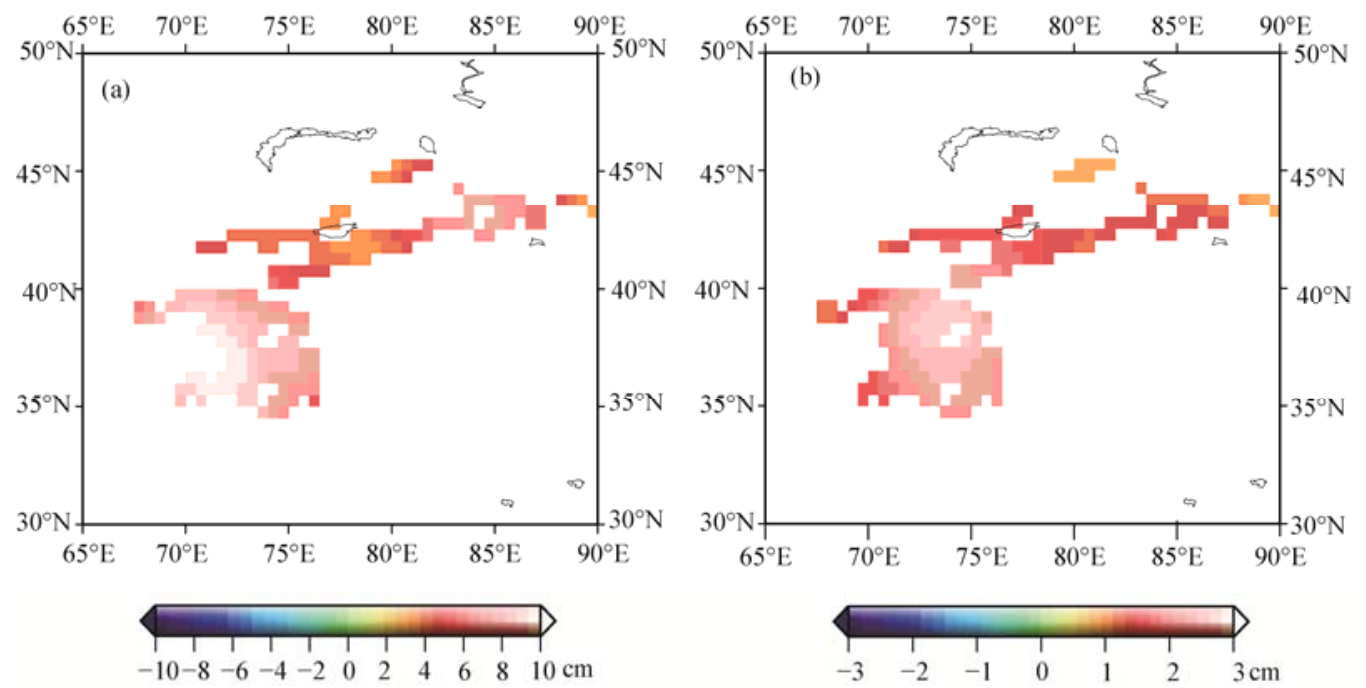

Fig. 6 Differences in spatial patterns of the 6.1-year (a) and 2.3-year (b) oscillations between extreme high and extreme low phases 


\subsubsection{Relationship between inter-annual oscillations and precipitation}

A strong correlation between glacier mass balance and precipitation was previously found over Central Asia (Yi and Sun, 2014). To determine the relationship between the inter-annual oscillations in glacier mass and precipitation over Central Asia, we used the monthly precipitation dataset from the Tropical Rainfall Measuring Mission (TRMM) (Huffman et al., 2007). And the precipitation data were processed in the same way as the GRACE data. The TRMM gridded fields were adjusted into the same degree and order as GARCE data. After the same Gaussian filter used on GRACE was applied, the monthly precipitation data were then interpolated to fit into the glacier mask of the Central Asia. When MSSA was performed on the first ten S-PCs of monthly filtered precipitation data, the 6.1-year oscillation was well captured by the first and second eigenmodes, which accounts for $30.4 \%$ of the total variance. For the 6.1 -year oscillation, the lagged cross-correlation function was computed between MSSA-filtered glacier mass and precipitation on each grid as a function of lead time in precipitation. Figure 7 shows the 6.1-year oscillations for glacier mass and precipitation and corresponding lagged cross-correlation between them at grid point $\left(39.25^{\circ} \mathrm{N}, 67.75^{\circ} \mathrm{E}\right)$. The change in the glacier mass was lagged about 13 months behind the precipitation change (Fig. 7a), and the corresponding cross-correlation result shows a significant positive time lagging (Fig. 7b). Figure 8 shows the spatial patterns of the lag time of glacier mass responses to the precipitation over Central Asia. Generally speaking, the glacier mass over Central Asia was lagged behind the precipitation by 9-16 months with an average of 13 months in terms of the 6.1-year oscillation. However, the lagging effect was not detected for the 2.3-year oscillation.
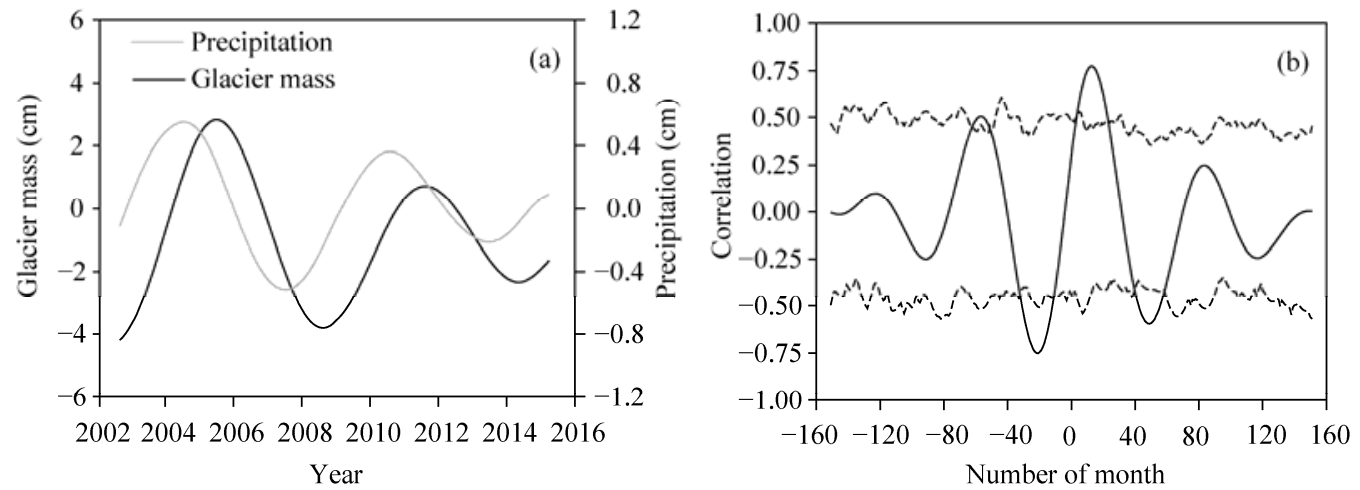

Fig. 7 (a) The 6.1-year oscillations for glacier mass and precipitation at grid point $\left(39.25^{\circ} \mathrm{N}, 67.75^{\circ} \mathrm{E}\right)$; $(\mathrm{b})$ Corresponding cross-correlation coefficient between the two at grid point $\left(39.25^{\circ} \mathrm{N}, 67.75^{\circ} \mathrm{E}\right)$

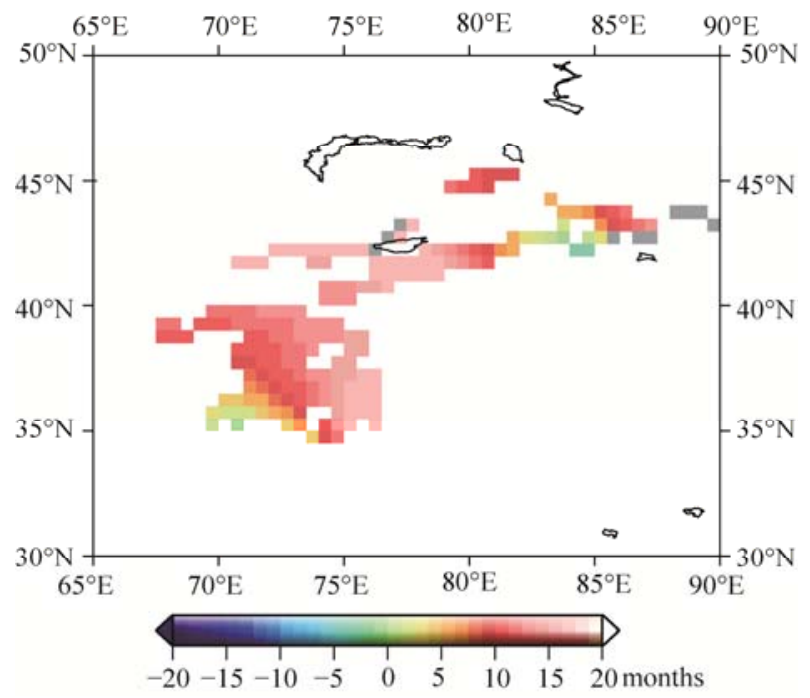

Fig. 8 Spatial patterns of the lag time of glacier mass responses to the precipitation on each grid (in the 6.1-year oscillation) 


\subsection{Temporal trends of glacier mass}

We conducted the time series analysis to detect possible trends existed in ST-RC3 and ST-RC4 data (denoted as STRCs34) and ST-RC1,2, ST-RC3,4 and ST-RC7,8 data (denoted as STRCs123478) of glacier mass over the Tianshan Mountains and the Pamir Plateau (Fig. 9). The results based on the data of STRCs34 only express the general decreasing trends over both the Tianshan Mountains and the Pamir Plateau (i.e., dashed lines in Figs. 9a and b). However, the results based on the data of STRCs 12345678 show large-amplitude fluctuations in glacier mass during the period from 2002 to 2015 over both the Tianshan Mountains and the Pamir Plateau (i.e., light-grey lines in Figs. 9a and b). It is clear that inter-annual oscillations are obviously superimposed upon trend in STRCs123478, which can affect the glacier mass trend at short time intervals.

According to published estimates, glacier mass trends over Central Asia inferred from GRACE data differed at different time periods (Matsuo and Heki, 2010; Jacob et al., 2012; Gardner et al., 2013; Yi and Sun, 2014). And this was usually caused by two reasons. Firstly, leakage effect and signal attenuation caused by smoothing and limited spatial resolution made GRACE data problematic to estimate glacier mass trend (Wouters et al., 2008; Chen et al., 2013). Secondly, glacier mass trend from GRACE data might also be affected by the measurement errors in the gravity fields and uncertainty of the background geophysical models used in GRACE data processing (Velicogna and Wahr, 2013). Although the discrepancy of the estimates, the results confirmed the importance of modelling of inter-annual oscillations of glacier mass over Central Asia based on the method.
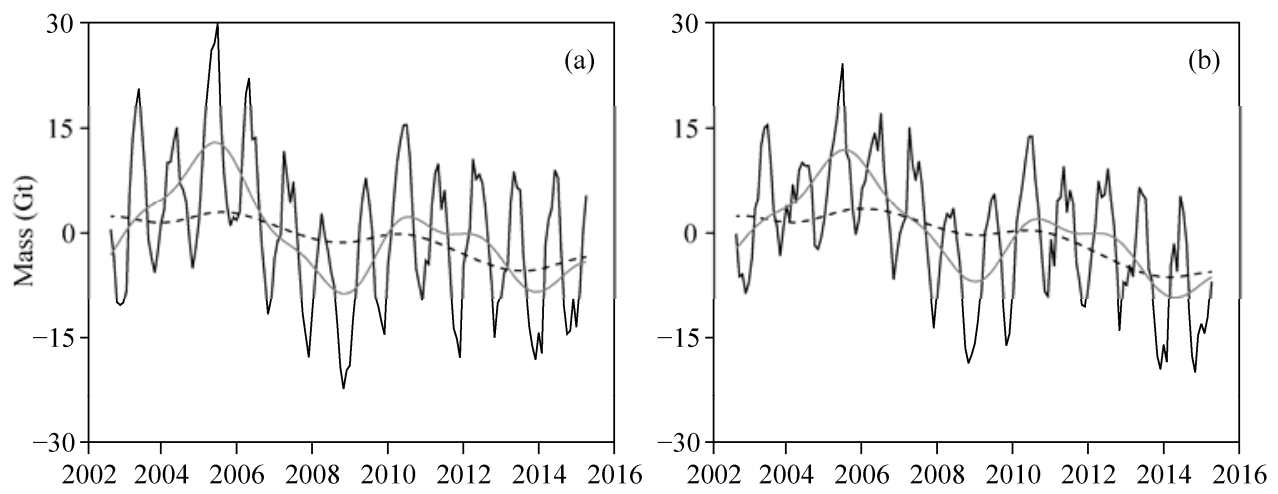

Fig. 9 The trends based on STRCs34 data (dashed line) and STRCs123478 data (light-grey line) in glacier mass over the Tianshan Mountains (a) and the Pamir Plateau (b)

\section{Conclusions}

In this study, we found two significant inter-annual oscillations in glacier mass over Central Asia by using the data of GRACE L2 obtained during the period from 2002 to 2015 . The inter-annual oscillations with a period of 6.1-year and a period of 2.3 -year accounted for $54.5 \%$ and $4.3 \%$ of the total variance, respectively. Moreover, the 6.1-year glacier mass oscillation exhibited a stronger variability than the 2.3-year glacier mass oscillation. For the 6.1-year oscillation, the cross-correlation result suggests the glacier mass was lagged behind the precipitation by 9-16 months over Central Asia. That is, the glacier mass has responded to the precipitation with a time lag of 9-16 months. Our results may be helpful to clarify some inconsistencies in previous estimates from GRACE data over Central Asia. But, we are not yet able to depict the longer-term change of glacier mass simply due to the fact the GRACE data-covering period is too short. It certainly calls for long-term and continuous measurement of satellite gravity to quantify the long-term trends of glaciers over Central Asia. Fortunately, the GRACE Follow-On mission is currently under plan to replace the existing twin GRACE satellites. And the pilot studies for a Next Generation Gravity Mission (NGGM) are also being promoted by European Space Agency to monitor the time-variable gravity field with high temporal and spatial resolutions. 


\section{Acknowledgements}

This work was funded by the National Basic Research Program of China (2012CB957703, 2013CB733301), and the National Natural Science Foundation of China (41274025, 41174064). Cordial thanks should be extended to the Center for Space Research (CSR) at the University of Texas at Austin.

\section{References}

Arendt A, Bolch T, Cogley J G, et al. 2012. Randolph Glacier Inventory-A Dataset of Global Glacier Outlines: Version 3.2. Boulder Colorado, USA: Global Land Ice Measurements from Space.

Bettadpur S. 2003. Level-2 Gravity Field Product User Handbook. The GRACE Project. University of Texas: CSR Publication.

Burg J P. 1967. Maximum entropy spectral analysis. In: Proceedings of the $37^{\text {th }}$ Annual International Meeting. Society of Exploration Geophysics. Oklahoma, USA.

Chambers D P, Bonin J A. 2012. Evaluation of Release-05 GRACE time-variable gravity coefficients over the ocean. Ocean Science Discussions, 9(3): 2187-2214.

Chen J L, Wilson C R, Tapley B D. 2006. Satellite gravity measurements confirm accelerated melting of Greenland ice sheet. Science, 313(5795): 1958-1960.

Chen J L, Wilson C R, Tapley B D. 2011. Interannual variability of Greenland ice losses from satellite gravimetry. Journal of Geophysical Research: Solid Earth, 116(B7): B07406.

Chen J L, Wilson C R, Tapley B D. 2013. Contribution of ice sheet and mountain glacier melt to recent sea level rise. Nature Geoscience, 6(7): 549-552.

Cheng M K, Tapley B D. 2004. Variations in the Earth's oblateness during the past 28 years. Journal of Geophysical Research: Solid Earth, 109(B9): B09402.

Cowan P J. 2007. Geographic usage of the terms Middle Asia and Central Asia. Journal of Arid Environments, 69(2): 359-363.

de Linage C, Kim H, Famiglietti J S, et al. 2013. Impact of Pacific and Atlantic sea surface temperatures on interannual and decadal variations of GRACE land water storage in tropical South America. Journal of Geophysical Research: Atmospheres, 118(19): 10811-10829.

Duan J B, Shum C K, Guo J Y, et al. 2012. Uncovered spurious jumps in the GRACE atmospheric de-aliasing data: potential contamination of GRACE observed mass change. Geophysical Journal International, 191(1): 83-87.

Farinotti D, Longuevergne L, Moholdt G, et al. 2015. Substantial glacier mass loss in the Tien Shan over the past 50 years. Nature Geoscience, 8(9): 716-722.

Flechtner F. 2007. AOD1B Product Description Document for Product Releases 01 to 04 (Rev. 3.1, April 13, 2007). Postdam: University of Texas, 327-750.

Gardner A S, Moholdt G, Cogley J G, et al. 2013. A reconciled estimate of glacier contributions to sea level rise: 2003 to 2009. Science, 340(6134): 852-857.

Geruo A, Wahr J, Zhong S J. 2013. Computations of the viscoelastic response of a 3-D compressible Earth to surface loading: an application to Glacial Isostatic Adjustment in Antarctica and Canada. Geophysical Journal International, 192(2): 557-572.

Ghil M, Allen M R, Dettinger M D, et al. 2002. Advanced spectral methods for climatic time series. Reviews of Geophysics, 40(1): $1-41$.

Huffman G J, Bolvin D T, Nelkin E J, et al. 2007. The TRMM multisatellite precipitation analysis (TMPA): Quasi-global, multiyear, combined-sensor precipitation estimates at fine scales. Journal of Hydrometeorology, 8(1): 38-55.

Immerzeel W W, Van Beek L P H, Bierkens M F P. 2010. Climate change will affect the Asian water towers. Science, 328(5984): $1382-1385$.

Jacob T, Wahr J, Pfeffer W T, et al. 2012. Recent contributions of glaciers and ice caps to sea level rise. Nature, 482(7386): 514-518.

Kononova N K, Pimankina N V, Yeriskovskaya L A, et al. 2015. Effects of atmospheric circulation on summertime precipitation variability and glacier mass balance over the Tuyuksu Glacier in Tianshan Mountains, Kazakhstan. Journal of Arid Land, 7(5): 687-695.

Lioubimtseva E, Henebry G M. 2009. Climate and environmental change in arid Central Asia: Impacts, vulnerability, and adaptations. Journal of Arid Environments, 73(11): 963-977.

Luthcke S B, Arendt A A, Rowlands D D, et al. 2008. Recent glacier mass changes in the Gulf of Alaska region from GRACE mascon solutions. Journal of Glaciology, 54(188): 767-777.

Matsuo K, Heki K. 2010. Time-variable ice loss in Asian high mountains from satellite gravimetry. Earth and Planetary Science 
Letters, 290(1-2): 30-36.

Plaut G, Vautard R. 1994. Spells of low-frequency oscillations and weather regimes in the Northern Hemisphere. Journal of the Atmospheric Sciences, 51(2): 210-236.

Rodell M, Houser P R, Jambor U, et al. 2004. The global land data assimilation system. Bulletin of the American Meteorological Society, 85(3): 381-394.

Sasgen I, Dobslaw H, Martinec Z, et al. 2010. Satellite gravimetry observation of Antarctic snow accumulation related to ENSO. Earth and Planetary Science Letters, 299(3-4): 352-358.

Schrama E J O, Wouters B, Rietbroek R. 2014. A mascon approach to assess ice sheet and glacier mass balances and their uncertainties from GRACE data. Journal of Geophysical Research: Solid Earth, 119(7): 6048-6066.

Sorg A, Bolch T, Stoffel M, et al. 2012. Climate change impacts on glaciers and runoff in Tien Shan (Central Asia). Nature Climate Change, 2(10): 725-731.

Stocker T F, Qin D H, Plattner G-K, et al. 2013. Climate Change 2013: The Physical Science Basis. Intergovernmental Panel on Climate Change, Working Group I Contribution to the IPCC Fifth Assessment Report (AR5). New York: Cambridge University Press.

Swenson S, Chambers D, Wahr J. 2008. Estimating geocenter variations from a combination of GRACE and ocean model output. Journal of Geophysical Research: Solid Earth, 113(B8): B08410.

Swenson S, Wahr J. 2006. Post-processing removal of correlated errors in GRACE data. Geophysical Research Letters, 33(8): L08402.

Tapley B D, Bettadpur S, Ries J C, et al. 2004a. GRACE measurements of mass variability in the Earth system. Science, 305(5683): 503-505.

Tapley B D, Bettadpur S, Watkins M, et al. 2004b. The gravity recovery and climate experiment: Mission overview and early results. Geophysical Research Letters, 31(9): L09607.

Unal Y S, Ghil M. 1995. Interannual and interdecadal oscillation patterns in sea level. Climate Dynamics, 11(5): $255-278$.

Unger-Shayesteh K, Vorogushyn S, Farinotti D, et al. 2013. What do we know about past changes in the water cycle of Central Asian headwaters? A review. Global and Planetary Change, 110: 4-25.

Vautard R, Ghil M. 1989. Singular spectrum analysis in nonlinear dynamics, with applications to paleoclimatic time series. Physica D: Nonlinear Phenomena, 35(3): 395-424.

Vautard R, Yiou P, Ghil M. 1992. Singular-spectrum analysis: A toolkit for short, noisy chaotic signals. Physica D: Nonlinear Phenomena, 58(1-4): 95-126.

Velicogna I, Wahr J. 2006. Measurements of time-variable gravity show mass loss in Antarctica. Science, 311(5768): 1754-1756.

Velicogna I, Wahr J. 2013. Time-variable gravity observations of ice sheet mass balance: Precision and limitations of the GRACE satellite data. Geophysical Research Letters, 40(12): 3055-3063.

Wahr J, Molenaar M, Bryan F. 1998. Time variability of the Earth's gravity field: Hydrological and oceanic effects and their possible detection using GRACE. Journal of Geophysical Research: Solid Earth, 103(B12): 30205-30229.

Wouters B, Chambers D, Schrama E J O. 2008. GRACE observes small-scale mass loss in Greenland. Geophysical Research Letters, 35(20): L20501.

Xu L G, Zhou H F, Du L, et al. 2015. Precipitation trends and variability from 1950 to 2000 in arid lands of Central Asia. Journal of Arid Land, 7(4): 514-526.

Yao T D, Wang Y Q, Liu S Y, et al. 2004. Recent glacial retreat in High Asia in China and its impact on water resource in Northwest China. Science in China Series D: Earth Sciences, 47(12): 1065-1075.

Yao T D, Thompson L, Yang W, et al. 2012. Different glacier status with atmospheric circulations in Tibetan Plateau and surroundings. Nature Climate Change, 2(9): 663-667.

Yi S, Sun W K. 2014. Evaluation of glacier changes in high-mountain Asia based on 10 year GRACE RL05 models. Journal of Geophysical Research: Solid Earth, 119(3): 2504-2517. 